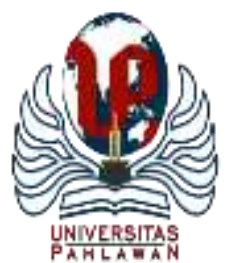

Edukatif : Jurnal Ilmu Pendidikan Volume 3 Nomor 6 Tahun 2021 Halm 4066 - 4074

EDUKATIF: JURNAL ILMU PENDIDIKAN

Research \& Learning in Education

https://edukatif.org/index.php/edukatif/index

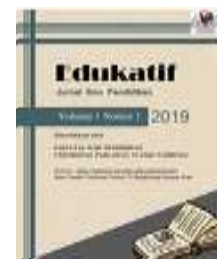

\title{
Pengaruh Model Pembelajaran Kooperatif Tipe Group Investigation terhadap Hasil Belajar Siswa pada Pembelajaran Tematik di Sekolah Dasar
}

\author{
Riani Angreni Buaton ${ }^{1 凶}$, Anton Sitepu², Darinda Sofia Tanjung ${ }^{3}$ \\ Universitas Katolik Santo Thomas Medan, Indonesia ${ }^{1,2,3}$ \\ E-mail : $\underline{\text { rianiibuaaton9@ gmail.com }}^{1}$, antonsitepu30@ gmail.com ${ }^{2},{\underline{\text { darinda tanjung@ } \text { ust.ac.id }^{3}}}^{3}$
}

\begin{abstract}
Abstrak
Penelitian ini bertujuan untuk mengetahui pengaruh penggunaan model pembelajaran kooperatif tipe group investigation terhadap hasil belajar siswa pada tema daerah tempat tinggalku di SD Swasta Advent Timbang Deli Medan kelas IV pada tahun 2020/2021. Jenis Penelitian ini adalah kuantitatif dengan menggunakan metode deskriptip analitik. Populasi dalam penelitian ini seluruh siswa kelas IV yang diteliti satu kelas berjumlah 35 siswa. Pengambilan sampel dengan menggunakan sampling jenuh. Berdasarkan hasil penelitian ini menunjukan bahwa hasil belajar siswa dengan menggunakan model pembelajaran kooperatif tipe group investigation termasuksud kategori sangat baik dengan rata-rata 87,23. Hasil penelitian ini menunjukan bahwa hasil pengujian korelasi dapat dilihat pada nilai koefisien korelasi sebesar 0,640 artinya $r_{\text {hitung }}(0,640)>$ $\mathrm{r}_{\text {tabel }}(0,361)$ maka $\mathrm{h}_{\mathrm{a}}$ diterima maka terdapat pengaruh yang kuat antara model pembelajaran kooperatif tipe group investigation terhadap hasil belajar siswa pada tema daerah tempat tinggalku di kelas IV SD Swasta Advent Timbang Deli Medan dapat juga dilihat dari hasil pengujian uji-t dimana $t_{\text {hitung }}>\mathrm{t}_{\text {tabel }}$ yaitu 4,786 > 1,703 sehingga menyatakan bawah hipotesis $\mathrm{H}_{\mathrm{a}}$ diterima.
\end{abstract}

Kata Kunci: Model Pembelajaran Group Investigation, Hasil Belajar Siswa

\section{Abstract}

This study aims to determine the effect of the use of the group investigation type cooperative learning model on student learning outcomes on the theme of the area where I live in the fourth grade Adventist Elementary School in Timbang Deli Medan in 2020/2021. This type of research is quantitative using analytical descriptive method. The population in this study was all fourth grade students studied in one class totaling 35 students. Sampling using saturated sampling. Based on the results of this study, it shows that student learning outcomes using the group investigation type cooperative learning model are included in the very good category with an average of 87.23. The results of this study indicate that the results of the correlation test can be seen in the correlation coefficient value of 0.640 , meaning that rcount $(0.640)>$ rtable $(0.361)$ then ha is accepted, so there is a strong influence between the group investigation type cooperative learning model on student learning outcomes on the theme of the area where I live in the fourth grade of Timbang Deli Medan Private Elementary School, it can also be seen from the results of the t-test where tcount > ttable is 4,786 > 1,703 so that it states that the hypothesis Ha is accepted.

Keywords: Group investigation learning model, Student Learning Outcomes

Copyright (c) 2021 Riani Angreni Buaton, Anton Sitepu, Darinda Sofia Tanjung

$\triangle$ Corresponding author:

Email : rianiibuaaton9@gmail.com

DOI : https://doi.org/10.31004/edukatif.v3i6.1398

ISSN 2656-8063 (Media Cetak)

ISSN 2656-8071 (Media Online)

Edukatif : Jurnal Ilmu Pendidikan Vol 3 No 6 Tahun 2021 p-ISSN 2656-8063 e-ISSN 2656-8071 
4067 Pengaruh Model Pembelajaran Kooperatif Tipe Group Investigation terhadap Hasil Belajar Siswa pada Pembelajaran Tematik di Sekolah Dasar - Riani Angreni Buaton, Anton Sitepu, Darinda Sofia Tanjung

DOI: https://doi.org/10.31004/edukatif.v3i6.1398

\section{PENDAHULUAN}

Pendidikan adalah usaha yang dilakukan dengan sengaja dan sistematis untuk memotivasi, membina, membantu, serta membimbing seseorang untuk mengembangkan segala potensinya sehingga ia mencapai kualitas diri yang lebih baik. Pendidikan adalah usaha pendewasaan manusia seutuhnya (lahir dan batin), baik oleh dirinya sendiri maupun orang lain, dalam arti tuntutan agar anak didik memiliki kemerdekaan berpikir, merasa, berbicara, dan bertindak serta percaya diri dengan penuh rasa tanggung jawab dalam setiap tindakan dan perilaku sehari-hari.

Belajar ialah suatu proses usaha yang dilakukan seseorang untuk memperoleh suatu perubahan tingkah laku yang baru secara keseluruhan, sebagai hasil pengalamannya sendiri dalam interaksi dengan lingkungannya". Seseorang yang belajar akan menyadari terjadinya perubahan itu atau sekurang kurangnya ia merasahkan terjadi adanya suatu perubahan dalam dirinya. Misalnya ia menyadari bahwa pengetahuanya bertambah, kecakapannya bertambah, kebiasaanya bertambah.

Hasil belajar adalah suatu pernyataan yang spesifik yang dinyatakan dalam prilaku dan penampilan yang diwujudkan dengan bentuk tulisan angka maupun tulisan agar dapat mengukur keberhasilan dari proses belajar yang telah diharapkan untuk mengetahui akan keberhasilan siswa sejauh mana siswa dapat memahami dan dapat menerima akan pelajaran yang telah mereka terima dari guru. Oleh karena itu,hasil belajar adalah suatu pernyataan yang jelas dan menunjukan penampilan atau keterampilan serta pengetahuan dalam belajar siswa tertentu yang telah diharapkan dapat dicapai sebagai hasil belajar.

Hasil belajar bertujuan untuk mengukur keberhasilan siswa dalam pembelajaran yang dilakukan guru dan sekaligus mengukur keberhasilan belajar siswa dalam memahami materi pembelajaran. Guru juga bisa melakukan refleksi dan evaluasi terhadap kualitas pembelajaran yang telah dilakukan. Refleksi yang bisa dilakukan guru meliputi: metode, strategi, media, model pembelajaran yang mungkin seorang guru dapat menerapkan atau melakukannya dalam proses pembelajaran berlangsung. Agar materi itu dapat dipahami dan dikuasai oleh siswa. Jika hasil belajar siswa meningkat maka dapat dikatakan guru berhasil. Apabila hasil belajar siswa turun berarti dapat dikatakan guru gagal dalam melakukan proses pembelajaran.

Berdasarkan observasi dan wawancara pada bulan Januari 2021, peneliti melakukan observasi di SD Swasta Advent Timbang Deli Medan peneliti memperoleh informasi bahwa guru masih dominan menggunakan model lama dengan metode ceramah, tanya jawab dan penugasan. Maka proses kegiatan belajar mengajar hanya berpusat pada guru, hingga siswa kurang aktif dalam kegiatan pembelajaran, Pada saat guru menjelaskan didepan kelas, guru hanya monoton terhadap papan tulis, dan siswa menulis ulang dibuku tulis. Pada saat ujian lebih banyak siswa mendapat nilai dibawah KKM, sehingga siswa belum memahami materi pembelajaran yang disampaikan oleh guru pada saat kegiatan proses pembelajaran berlangsung. Rendahnya hasil belajar siswa dikarenakan guru tidak menggunakan model pembelajaran bervariasi yang membosankan dan berdampak pada hasil belajar siswa.

Menurut Istarani (2018: 87) model pembelajaran group investigation adalah model pembelajaran yang dimulai dengan pembagian kelompok. Selanjutnya guru beserta anak didik memilih topik-topik tertentu sesuai permasalahan-permasalahan yang dapat dikembangkan dari topik-topik itu. Setelah topik dan permasalahannya sudah disepakati, peserta didik beserta guru menentukan model penelitian yang dikembangkan untuk memecahkan masalah.

Sedangkan menurut Huda (2017: 293) model pembelajaran group investigation yang pertama kali dikembangkan oleh Shara dan Sharan ini merupakan salah satu metode kompleks dalam pembelajaran kelompok yang mengharuskan siswa untuk menggunakan skill berpikir level tinggi. Pada prinsipnya, strategi GI (group investigation) sudah banyak diadopsi oleh berbagi bidang pengetahuan, baik humaniora maupun 
4068 Pengaruh Model Pembelajaran Kooperatif Tipe Group Investigation terhadap Hasil Belajar Siswa pada Pembelajaran Tematik di Sekolah Dasar - Riani Angreni Buaton, Anton Sitepu, Darinda Sofia Tanjung

DOI: https://doi.org/10.31004/edukatif.v3i6.1398

saintifik. Akan tetapi, dalam konteks pembelajaran metode GI (group investigation) tetap menekankan pada hetap menekan pada heterogenitas dan kerja sama antar siswa.

Shoimin (2019: 81) menyebutkan bahwa model pembelajaran group investigation adalah suatu model pembelajaran yang lebih menekankan pada pilihan dan kontrol siswa dari pada menerapkan teknik-teknik pengajaran di ruang kelas. Selain itu juga memadukan prinsip belajar demokratis di mana siswa terlibat secara aktif dalam kegiatan pembelajaran, baik dari tahap awal sampai akhir pembelajaran termasuk di dalamnya siswa mempunyai kebebasan untuk memilih materi yang akan dipelajari sesuatu dengan topik yang sedang dibahas.

Sedangkan menurut Slamento (2019: 2) belajar ialah suatu proses usaha yang dilakukan seseorang untuk memperoleh suatu perubahan tingkah laku yang baru secara keseluruhan, sebagai hasil pengalamannya sendiri dalam interaksi dengan lingkungan. Belajar diartikan sebagai proses perubahan perilaku tetap dari belum tau menjadi tahu, dari tidak paham menjadi paham menjadi paham, dari kurang terampil menjadi lebih terampil dan dari kebiasaan lama menjadi kebiasaan baru, serta bermanfaat bagi lingkungan maupun individu itu sendiri.

Menurut Komara (2020: 2) mengatakan ciri khas belajar adalah perubahan, yaitu belajar menghasilkan perubahan perilaku dalam diri peserta didik. Belajar menghasilkan perubahan perilaku yang secara relative tetap dalam berpikir, merasa dan melakukan pada diri peserta didik. Perubahan tersebut terjadi sebagai hasil latihan, pengalaman, pengembangan yang hasilnya tidak dapat diamati secara langsung.

Menurut Istarani dan Pulungan (2020: 86) hasil belajar adalah suatu pernyataan yang spesifik yang dinyatakan dalam prilaku dan penampilan yang diwujudkan dalam bentuk tulisan untuk menggambarkan hasil belajar yang diharapkan. Perilaku ini dapat berupa fakta yang konkrit serta dapat dilihat". Oleh karena itu, hasil belajar adalah suatu pernyataan yang jelas dan menunjukkan penampilan atau keterampilan siswa tertentu yang diharapkan dapat dicapai sebagai hasil belajar.

Selanjutnya Istarani dan Pulungan (2020: 86) menyatakan bahwa hasil belajar dapat membantu dalam mendesain sistem pembelajaran. Artinya dengan hasil yang jelas dapat membantu guru dalam menentukan materi pelajaran, metode, atau strategi pembelajaran, alat, media, sumber belajar, serta dalam menentukan alat evaluasi untuk melihat keberhasilan belajar siswa

Pembelajaran tematik merupakan salah satu pembelajaran terpadu (integrated instruction) yang merupakan suatu sistem pembelajaran yang memungkinkan siswa, baik secara individual maupun kelompok, aktif menggali dan menemukan konsep serta prinsip-prinsip keilmuan secara holistik, bermakna, dan autentik. Pembelajaran terpadu berorientasi pada praktik pembelajaran yang sesusai dengan kebutuhan dan perkembangan siswa. Pendekatan ini berangkat dari teori pembelajaran yang menolak proses latihan/hafalan sebagai dasar pembentukan pengetahuan dan struktur Intelektual anak. Teori pembelajaran ini dimotori para tokoh psikologi Gestalt, termasuk piaget yang menekankan bahwa pembelajaran itu haruslah bermakna dan berorientasi pada kebutuhan dan perkembangan anak. Pendekatan pembelajaran terpadu lebih menekankan pada penerapan konsep belajar sambil melakukan sesuatu.

Dalam pelaksanaanya, pendekatan pembelajaraan tematik ini bertolak dari satu tema yang dipilih dan dikembangkan oleh guru bersama siswa dengan memerhatikan keterkaitannya dengan isi mata pelajaran. Tema adalah pokok pikiran atau gagasan pokok yang menjadi pokok pembicaraan. Tujuan dari adanya tema bukan hanya untuk menguasai konsep-konsep dalam suatu mata pelajaran, akan tetapi juga keterkaitannya dengan konsep-konsep dari mata pelajaran lainnya.

\section{METODE PENELITIAN}

Penelitian ini akan dilaksanakan pada siswa kelas IV SD Swasta Advent Timbang Deli Medan Tahun Ajaran 2020/2021. Tempat penelitian ini beralamat di Jln. Sisingamangaraja KM.X / Jln. Dame No.11-A 
4069 Pengaruh Model Pembelajaran Kooperatif Tipe Group Investigation terhadap Hasil Belajar Siswa pada Pembelajaran Tematik di Sekolah Dasar - Riani Angreni Buaton, Anton Sitepu, Darinda Sofia Tanjung

DOI: https://doi.org/10.31004/edukatif.v3i6.1398

Timbang Deli Medan Kota Deli Serdang Medan Sumatra Utara. Penelitian ini menggunakan menggunakan pendekatan kuantitatif dengan metode dekskriptik analiktik. Populasi dalam penelitian ini adalah seluruh siswa kelas IV semester II SD Swasta Advent Timbang Deli Meda Tahun Ajaran 2020/2021 yang berjumlah 35 siswa dengan teknik pengambilan sampel dilakuan dalam penelitian ini adalah dengan cara sampling jenuh. Jadi yang menjadi sampel dalam penelitian ini adalah kelas IV SD Swasta Advent Timbang Deli Medan yang berjumlah 35 orang.

Teknik pengumpulan data yang digunakan adalah tes, angket, dokumentasi. Sedangkan instrumen penelitian yang digunakan adalah lembar tes dan lembar angket. Teknik analisis data terdiri dari uji instrumen penelitian (uji validitas tes, uji reliabilitas) dengan uji persyaratan data menggunakan uji normalitas. Teknik pengolahan (analisis) data menggunakan uji koefisien korelasi dan uji hipotesis dengan menggunkan uji-t. Untuk pengujian data dan analisis data peneliti menggunakan bantuan program microsoft excel dan program spss versi 22 serta pengujian secara manual.

Menurut Arikunto (2017: 66), "Menyatakan bahwa tes merupakan alat atau prosedur yang digunakan untuk mengetahui atau mengukur sesuatu dalam suasana, dengan cara-cara dan aturan-aturan yang sudah di tentukan". Tes ini di gunakan untuk membantu siswa dan memahami materi yang dipelajari sebelumnya. Bentuk tes yang di gunakan peneliti adalah tes pilihan berganda, siswa diminta untuk memberikan jawaban yang benar dari pertanyaan yang disusun.

Setelah uji validitas instrument sial kepada 35 orang siswa dengan berjumlah 50 butir soal. Dari 50 instrumen soal yang diuji coba terdapat 28 instrument soal yang dinyatakan valid dengan $\mathrm{r}_{\text {hitung }}>\mathrm{r}_{\text {tabel }}$ Sedangkan 22 Soal yang dinyatakan tidak valid dengan $\mathrm{r}_{\text {hitung }}<\mathrm{r}_{\text {tabel. }}$

\section{HASIL DAN PEMBAHASAN PENELITIAN}

Hasil Pre Test yang telah dilaksanakan menunjukkan bahwa kemampuan hasil belajar dikatakan cukup.

Tabel 1

Distribusi Frekuensi Nilai Pretest Kelas I

\begin{tabular}{ccccc}
\hline No & Nilai & Frekuensi & Persentase & Kategori \\
\hline 1 & $16-28$ & 2 & $5,71 \%$ & Gagal \\
\hline 2 & $29-40$ & 5 & $14,28 \%$ & Cukup \\
\hline 3 & $41-52$ & 7 & $20 \%$ & Gagal \\
\hline 4 & $53-64$ & 15 & $42.85 \%$ & Baik \\
\hline 5 & $65-76$ & 4 & $11,42 \%$ & Kurang \\
\hline 6 & $77-88$ & 1 & $2,85 \%$ & Gagal \\
\hline 7 & $89-100$ & 1 & $2,85 \%$ & Baik \\
\hline & Jumlah & 35 & $100 \%$ & \\
\hline
\end{tabular}

Berdasarkan tabel distribsui frekuensi nilai Pretest kelas IV diperoleh nilai tertinggi 90 dan nilai terendah 16. Diperoleh rata-rata (mean) sebesar 53,57 dan standar deviasi sebesar 16,276 Siswa yang memperoleh nilai di atas rata-rata (mean) sebanyak 21 siswa dengan presentase 59,97\% dan siswa yang memperoleh nilai dibawah rata-rata (mean) sebanyak 14 siswa dengan presentase 19,99\%. Dengan presentase tertinggi $42.85 \%$ dan persentase terenduh sebesar $2,85 \%$.

Tabel 2

Distribusi Frekuensi Nilai Posttest Kelas IV

\begin{tabular}{ccccc}
\hline No. & Nilai & Frekuensi & Persentase & Kategori \\
\hline 1 & $69-75$ & 3 & $8,57 \%$ & Gagal \\
\hline 2 & $76-82$ & 6 & $17,14 \%$ & Gagal \\
\hline 3 & $83-89$ & 13 & $37,14 \%$ & Baik \\
\hline
\end{tabular}


4070 Pengaruh Model Pembelajaran Kooperatif Tipe Group Investigation terhadap Hasil Belajar Siswa pada Pembelajaran Tematik di Sekolah Dasar - Riani Angreni Buaton, Anton Sitepu, Darinda Sofia Tanjung

DOI: https://doi.org/10.31004/edukatif.v3i6.1398

\begin{tabular}{ccccc}
\hline 4 & $90-100$ & 13 & $37,14 \%$ & Baik \\
\hline & Jumlah & $\mathbf{3 5}$ & $\mathbf{1 0 0 \%}$ & \\
\hline
\end{tabular}

Berdasarkan tabel distribusi nilai Posttest kelas IV diperoleh nilai tertinggi 100 dan nilai terendah 69 . Diperoleh rata-rata (mean) sebesar 87,23 dan standart deviasi sebesar 7,361 siswa yang memperoleh nilai diatas rata-rata (mean) sebanyak 26 siswa dengan persentase $74,28 \%$ dan siswa yang memperoleh nilai di bawah rata-rata (mean) sebanyak 9 Siswa dengan persentase $25,71 \%$. Dengan presentase tertinggi 37,14\% dan persentase terendah sebesar $8,57 \%$.

Hasil nilai Posttest menunjukan bahwa ada peningkatan kekuntasan belajar siswa kelas IV. Hasil ini dapat dilihat dari nilai Posttest lebih tinggi dari pada nilai pretses. Dimana nilai rata-rata Posttest 87,23 sedangkan nilai Pretest 53,57 Untuk lebih jelasnya dapat dilihat dari nilai rata-rata Pretest dan Posttest pada diagram dibawah ini:

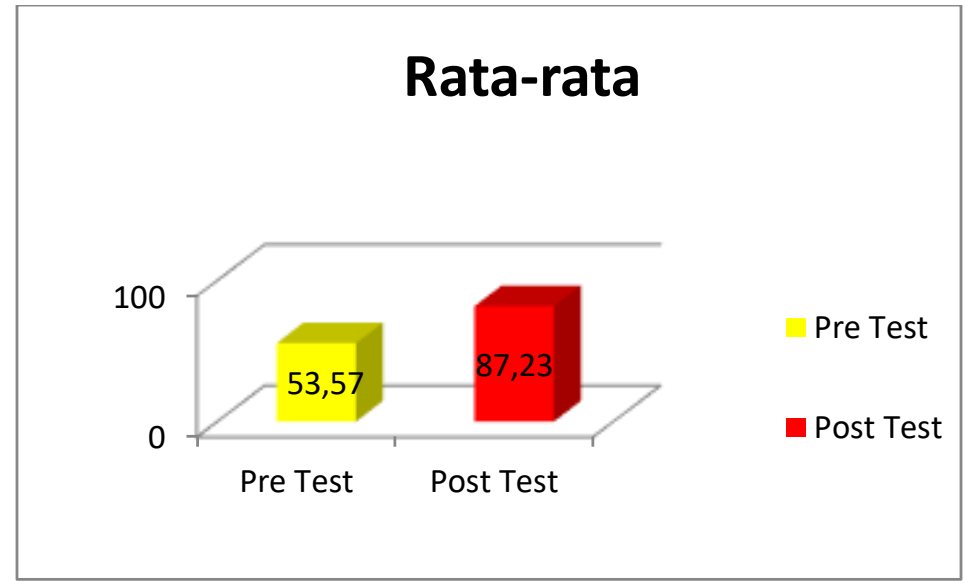

Gambar 1. Diagaram Nilai rata-rata Pretest dan Posttest kelas IV

Tabel 3

Distribusi Frekuensi Hasil Angket Model Group Investigation

\begin{tabular}{ccccc}
\hline No & Nilai & Frekuensi & Persentase & Kategori \\
\hline 1 & $49-52$ & 10 & $28,57 \%$ & Cukup \\
\hline 2 & $53-56$ & 20 & $57,14 \%$ & Baik \\
\hline 3 & $57-60$ & 5 & $14,28 \%$ & Gagal \\
\hline & Jumlah & 35 & $100 \%$ &
\end{tabular}

Berdasarkan tabel distribsui frekuensi nilai angket model Kooperatif tipe Group Investigation kelas IV diperoleh nilai tertinggi 58 dan nilai terendah 49. Diperoleh rata-rata (mean) sebesar 53,71 dan standar deviasi sebesar 2.456. Siswa yang memperoleh nilai di atas rata-rata (mean) sebanyak 25 orang dengan 71,38\% dan siswa yang memperoleh nilai dibawah rata-rata (mean) sebanyak 10 orang dengan $28,57 \%$. Dengan persentase tertinggi sebesar $57,14 \%$ dan persentase terendah sebesar $14,28 \%$ 
4071 Pengaruh Model Pembelajaran Kooperatif Tipe Group Investigation terhadap Hasil Belajar Siswa pada Pembelajaran Tematik di Sekolah Dasar - Riani Angreni Buaton, Anton Sitepu, Darinda Sofia Tanjung

DOI: https://doi.org/10.31004/edukatif.v3i6.1398

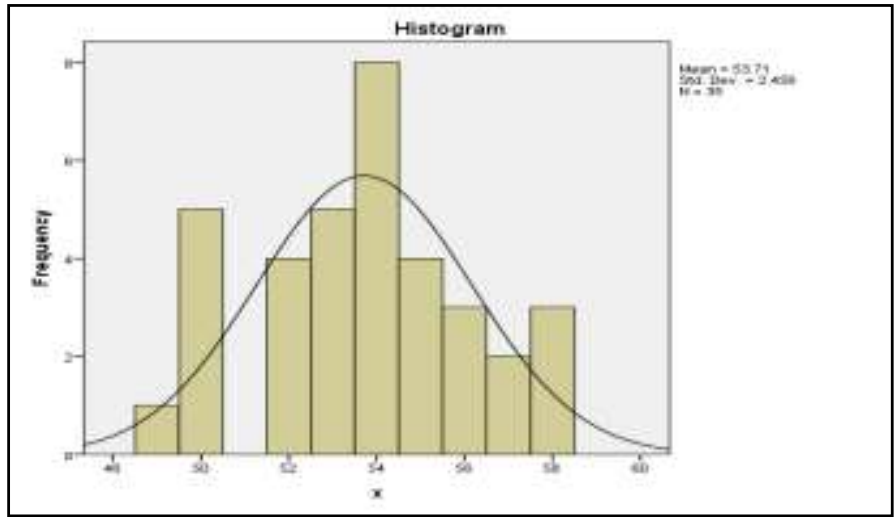

Gambar 2. Diagram hasil angket

Tabel 4

Uji Normalitas

Tests of Normality

\begin{tabular}{lccccccc}
\hline & \multicolumn{3}{c}{ Kolmogorov-Smirnov } & \multicolumn{3}{c}{ Shapiro-Wilk } \\
\cline { 2 - 8 } & Statistic & Df & Sig. & Statistic & df & Sig. \\
\hline Unstandardized Residual & .109 & 35 & $.200^{*}$ & .953 & 35 & .142 \\
\hline
\end{tabular}

*. This is a lower bound of the true significance.

a. Lilliefors Significance Correction

Pengambilan keputusan dengan mengambil taraf signifikasikan 5\% adalah sebagai berikut:

1. Nilai Signifikansi (sig) $<0,05$ distribusi tidak normal

2. Nilai Signifikansi (sig) $>0,05$ distribusi normal

Nilai taraf signifikansi yang digunakan oleh peneliti adalah taraf signifikansi $5 \%$ atau 0,05 . Berdasarkan uji liliefors (kolmogrov smirnov) didapatkan signifikansi sebesar 0,200 sehingga disimpulkan 0,200>0,05 maka data kelas IV berdistribusi normal. Selain itu, berdasarkan uji liliefors (Shapiro wilk) didapatkan sebesar 0,142 sehingga disimpulkan 0,142>0,05 maka data kelas IV berdistribusi normal. Perhitungan normalitas juga dapat melihat kriteria normalitas yaitu jika $\mathrm{L}_{\text {hitung }}<\mathrm{L}_{\text {tabel }}$ dapat dikatakan berdistribusi normal. Dapat disimpulkan dari hasil di atas diperoleh nilai signifikansi hasil belajar adalah $\mathrm{L}_{\text {hitung }}<\mathrm{L}_{\text {tabel }}$ yaitu $0,142<0,934$. Berdasarkan perhitungan tersebut dapat diketahui bahwa nilai signifikansi dari hasil belajar berdistribusi normal. Berikut gambar histogram dari normalitas:

\section{Tabel 5}

Uji Koefisien Korelasi

\begin{tabular}{|c|c|c|c|}
\hline \multicolumn{4}{|c|}{ Correlations } \\
\hline & & $\begin{array}{c}\text { Group } \\
\text { Investigation }\end{array}$ & Hasil Belajar \\
\hline \multirow[t]{3}{*}{ Group Investigation } & Pearson Correlation & 1 & $.640^{* *}$ \\
\hline & Sig. (2-tailed) & & .000 \\
\hline & $\mathrm{N}$ & 35 & 35 \\
\hline \multirow[t]{3}{*}{ Hasil Belajar } & Pearson Correlation & $.640^{* * *}$ & 1 \\
\hline & Sig. (2-tailed) & .000 & \\
\hline & $\mathrm{N}$ & 35 & 35 \\
\hline
\end{tabular}

Dari tabel di atas menujukkan bahwa nilai koefisien korelasi sebesar 0,650.Dari tabel di atas nilai koefisien korelasi sebesar 0,640 artinya $\mathrm{r}_{\text {hitung }}(0,640)>\mathrm{r}_{\text {tabel }}(0,361)$ Maka terdapat pengaruh yang kuat antara model pembelajaran Kooperatif group investigation terhadap hasil belajar siswa dan terdapat pengaruh antara model pembelajaran Kooperatif tipe Group Investigation terhadap hasil belajar siswa kelas IV SD 
4072 Pengaruh Model Pembelajaran Kooperatif Tipe Group Investigation terhadap Hasil Belajar Siswa pada Pembelajaran Tematik di Sekolah Dasar - Riani Angreni Buaton, Anton Sitepu, Darinda Sofia Tanjung

DOI: https://doi.org/10.31004/edukatif.v3i6.1398

Swasta Advent Timbang Deli Medan sebesar 64\% dan sebanyak 35\% dipengaruhi oleh faktor lain yang tidak dikaji dalam penelitian ini.

Statistik yang digunakan untuk menguji hipotesis penelitian adalah uji-t. Hipotesis yang diajukan adalah,

Ho: tidak ada pengaruh model pembelajaran Kooperatif tipe Group Investigation terhadap hasil belajar siswa Ha: ada pengaruh model pembelajaran Kooperatif tipe Group Investigation terhadap hasil belajar siswa

Kriteria uji-t dapat dikatakan signifikan apabila diperoleh harga $\mathrm{p}<0,05$. Serta hipotesis diterima (Ha) jika $\mathrm{t}_{\text {hitung }}>\mathrm{t}_{\text {tabel }}$ dan di tolak (Ho) jika $\mathrm{t}_{\text {hitung }}<\mathrm{t}_{\text {tabel }}$. Hasil perhitungan hipotesis uji $\mathrm{t}$ dapat dilihat pada tabel 4.9 di bawah ini:

Tabel 6

Uji-t

\begin{tabular}{|c|c|c|c|c|c|c|}
\hline \multicolumn{7}{|c|}{ Coefficients $^{\mathrm{a}}$} \\
\hline \multirow[b]{2}{*}{ Model } & & \multicolumn{2}{|c|}{ Unstandardized Coefficients } & $\begin{array}{l}\text { Standardized } \\
\text { Coefficients }\end{array}$ & \multirow[b]{2}{*}{$\mathrm{t}$} & \multirow[b]{2}{*}{ Sig. } \\
\hline & & $\mathrm{B}$ & Std. Error & Beta & & \\
\hline \multirow[t]{2}{*}{1} & (Constant) & -15.703 & 21.523 & & -.730 & .471 \\
\hline & Gruop Investigation & 1.916 & .400 & .640 & 4.786 & .000 \\
\hline
\end{tabular}

a. Dependent Variable: Hasil Belajar

Untuk mengetahui ada atau tidaknya pengaruh dapat dilihat hasil signifikan yang diperoleh $0,000<$ 0,05 . Hasil perhitungan uji-t dari SPSS ver 22 sebesar 4,531. Untuk mendukung hasil uji-t dari SPSS ver 22, maka berikut hasil uji-t secara manual. Dapat diketahui dari nilai $t_{\text {hitung }}>t_{\text {tabel }}$ yaitu 4,786 $>1,703$ yang artinya ada pengaruh model pembelajaran Kooperatif tipe Group Investigation terhadap hasil belajar siswa.

\section{KESIMPULAN}

Berdasarkan pembahasan bab ini peneliti menguraikan simpulan, implikasi, keterbatasan penelitian, dan saran yang disusun berdasarkan seluruh kegiatan penelitian mengenai pengaruh model pembelajaran Kooperatif tipe Group Investigation terhadap hasil belajar siswa kelas IV SD Swasta Advent Timbang Deli Medan Tahun Pembelajaran 2020/2021 sebagai berikut:

1. Pada kelas IV dengan materi pembelajaran tema Daerah Tempat Tinggalku Subtema Keunikan Tempat Tinggalku Pembelajaran di SD Swasta Advent Timbang Deli Medan Tahun Pebelajaran 2020/2021 kelas IV adalah nilai rata-rata Pretest 53,8 dengan kategori kurang.

2. Pada kelas IV dengan menggunakan model pembelajaran Kooperatif tipe Group Investigation pada mata materi tema Daerah Tempat Tinggalku subtema Keunikan Tempat Tinggalku Pembelajaran di SD Swasta Advent Timbang Deli Medan Tahun Pembelajaran 2020/2021 kelas adalah nilai rata-rata Posttest 87,13 berada dengan kategori baik sekali.

3. Pada Kelas IV dengan menggunakan model pembelajaran Kooperatif tipe Group Investigation pada mata materi tema Daerah Tempat Tinggalku Subtema Keunikan Tempat Tingalku Pembelajaran di SD Swasta Advent Timbang Deli Medan Tahun Pembelajaran 2021/2021 kelas IV hasil angket siswa rata-rata Angket Test 53,71 dengan kategori sangat tinggi.

4. Berdasarkan hasil normalitas dengan menggunakan taraf signifikan $5 \%$ atau 0,05 dengan $\mathrm{L}_{\text {hitung }}<\mathrm{L}_{\text {tabel }}$ yaitu $0,142<0,934$. Dari hasil uji korelasi sebesar 0,650 artinya $r_{\text {hitung }}>r_{\text {tabel }}$ yaitu $0,640>0,361$. Berdasarkan perhitungan hasil penelitian menunjukkan bahwa terdapat pengaruh model pembelajaran Kooperatif tipe Group Investigation terhadap hasil belajar siswa pada tema daerah tempat tinggalku subtema keunikan daerah tempat tinggalku di SD Swasta Advent Timbang Deli Medan Tahun Pembelajaran 2020/2021 dengan $t_{\text {hitung }}>t_{\text {tabel }}$ dimana 4,786>1,703 pada taraf signifikan $\alpha=0,05$. Siswa 
4073 Pengaruh Model Pembelajaran Kooperatif Tipe Group Investigation terhadap Hasil Belajar Siswa pada Pembelajaran Tematik di Sekolah Dasar - Riani Angreni Buaton, Anton Sitepu, Darinda Sofia Tanjung

DOI: https://doi.org/10.31004/edukatif.v3i6.1398

dengan tema daerah tempat tinggalku subtema keunikandaerah tempat tinggalku. Dengan demikian $\mathrm{H}_{\mathrm{a}}$ diterima dan $\mathrm{H}_{\mathrm{o}}$ ditolak.

5. Penelitian yang dilakukan oleh peneliti dengan menerapkan model pembelajaran Kooperatif tipe Group Investigation juga dapat meningkatkan hasil belajar siswa pada tema Daerah Tempat Tinggalku di kelas IV SD Swasta Advent Timbang Deli Medan Tahun Pembelajaran 2020/2021.

\section{UCAPAN TERIMA KASIH}

Peneliti mengucapkan puji syukur kepada Tuhan Yang Maha Esa karena atas kasih setia-Nya yang berlimpah penulis dapat menyelesaikan artikel ini dengan baik. Penulis juga tidak lupa mengucapkan terima kasih kepada dosen pembimbing serta semua orang yang terlibat dalam penulisan artikel ini.

\section{DAFTAR PUSTAKA}

Arikunto, S. (2016). Dasar-dasar Evaluasi Pendidikan. Jakarta: Bumi Aksara.

Girsang, P. D., Tanjung, D. S., \& Azelina, D. (2021). The Effect of Group Investigation Type Cooperative Learning Model on Students' Learning Outcomes on The Themes of Daerah Tempat Tinggalku at Grade IV SDN 094117 Bangun Saribu. 5(20), 252-261.

Huda. (2017). Model-model Pembelajaran dan Pengajaran. PUSTAKA PELAJAR.

Istarani. (2019). 58 Model Pembelajaran Inovatif. Media persada.

Istarani. Model Pembelajaran Inovatif. Media persada, 2019.

Istarani, Pulungan. 2019. Enskopedia Pendidikan. CV. ISKOM MEDAN,

Karo, T. B., Anzelina, D., Sembiring, N., \& Tanjung, D. S. (2021). Meningkatkan Hasil Belajar Siswa dengan Menggunakan Model Spider Webbed pada Pembelajaran Tematik. EDUKATIF: JURNAL ILMU PENDIDIKAN, 3(4), 2108-2117.

Nainggolan, M., Tanjung, D. S., \& Simarmata, E. J. (2021). Pengaruh Model Pembelajaran S AVI terhadap Hasil Belajar Matematika Siswa di Sekolah Dasar. Jurnal Basicedu, 5(4), 2617-2625.

Prasetyo, W. E., Kristin, F., \& Anugraheni, I. (2019). Penerapan Model Pembelajaran Cooperative Learning Tipe Group Investigation Untuk Meningkatkan Kerjasama Dan Hasil Belajar Mapel IPA Siswa Kelas 4. Edukatif: Jurnal Ilmu Pendidikan, 1(2), 64-71.

Pulungan, I. (2019). Ensiklopedia Pendidikan (2nd ed.). Media Persada.

Purba, F. B., Tanjung, D. S., \& Gaol, R. L. (2021). The Effect Of Paikem Approach On Students' Learning Outcomes on The Theme of Lingkungan Sahabat Kita At Grade V SD Harapan Baru Medan Academic Year 2019/2020. Jurnal PAJAR (Pendidikan Dan Pengajaran), 5(2), 278-286.

Purba, J. M., Sinaga, R., \& Tanjung, D. S. (2020). Pengaruh Model Pembelajaran Tipe Kooperatif Tipe Scramble terhadap Hasil Belajar Siswa pada Tema Daerah Tempat Tinggalku Kelas IV. ESJ (Elementary School Journal), 10(4), 216-224.

Saragih, L. M., Tanjung, D. S., \& Anzelina, D. (2021). Pengaruh Model Pembelajaran Open Ended t erhadap Hasil Belajar Siswa pada Pembelajaran Tem atik. Jurnal Basicedu, 5(4), 2644-2652.

Shoimin, A. (2019). 68 Model Pembelajaran Inovatif dalam Kurikuum 2013. Yogyakarta: Ar-Ruzz Media.

Slameto. (2019). Belajar dan Faktor-faktor yang mempengaruhi. RINEKA CIPTA.

Simorangkir, F. M. A., \& Tanjung, D. S. (2019a). Analisis Pelaksanaan Pembelajaran Tematik dengan Pendekatan Multiple Intelligencesberbasis Budaya Batak Angkola untuk Siswa Kelas IV Sekolah Dasar. Jurnal Education and Development, 7(4), 302-304. 
4074 Pengaruh Model Pembelajaran Kooperatif Tipe Group Investigation terhadap Hasil Belajar Siswa pada Pembelajaran Tematik di Sekolah Dasar - Riani Angreni Buaton, Anton Sitepu, Darinda Sofia Tanjung

DOI: https://doi.org/10.31004/edukatif.v3i6.1398

Simorangkir, F. M. A., \& Tanjung, D. S. (2019b). Implementation of Multiple Intelligences Approach Based On Batak Angkola Culture in Learning Thematic For Class IV SD Negeri 100620 Pargarutan Julu South Tapanuli District. Budapest International Research and Critics in Linguistics and Education (BirLE) Journal, 2(4), 547-551. https://doi.org/10.33258/birle.v2i4.538

Sinaga, R., \& Silaban, P. J. (2021). Jurnal basicedu. Pengaruh Model Pembelajaran PAIKEM Terhadap Hasil Belajar Siswa Di Sekolah Dasar, 5(1), 102-109.

Shoimin. 68 Model Pembelajaran Inovatif Dalam Kurikulum 2013. Edited by Rose KR, AR.RUZZ.MEDIA, 2019.

Simorangkir, Tanjung. Analisis Pelaksanaan Pembelajaran Tematik Dengan Pendekatan Multiple Intelligences Berbasis Budaya Batak Angkola Untuk Siswa Kelas IV Sekolah Dasar. 2019, p. 302.

Slameto. Belajar Dan Faktor-Faktor Yang Mempengaruhi. PT Asdi Mahasatya, 2019.

---. Belajar Dan Faktor-Faktor Yang Mempengaruhi. RINEKA CIPTA, 2019.

---. Belajar Dan Faktor-Faktor Yang Mempengaruhi. PT RINEKA CIPTA, 2019.

Slavin. Model Pembelajaran Kooperatif. PT.Nusa Media, 2016.

Sugiyono. Metode Penelitian Kuantitatif, Kualitatif,Dan R\&D. ALVABETA.cv, 2018.

Sumiati. Metode Pembelajaran. 2 mei 2020, Media persada, 2012.

Suwardi. Faktor Yang Mempengaruhui Hasil Belajar Siswa Kopetensi Dasar Ayat Jurnal Penyesuaian Matapelajaran Akutansi Kelas IX Ips Negri 1 Bae Kudus. 2012, p. 2.

Tanjung, D. S. (2016). Meningkatkan Hasil Belajar IPS dengan Menerapkan Model Pembelajaran Kooperatif Tipe Team Games Tournament (TGT) di Kelas V SDN 200111 Padangsidimpuan. Pendidikan Guru Sekolah Dasar, IV(1), 68-79.

Tarigan, E. B., Simarmata, E. J., Abi, A. R., \& Tanjung, D. S. (2021). Peningkatan Hasil Belajar Siswa dengan Menggunakan Model Problem Based Learning pada Pembelajaran Tematik. EDUKATIF: JURNAL ILMU PENDIDIKAN, 3(4), 2294-2304.

Tatang. (2014: 14). Ilmu Pendidikan. Bandung: PT. Pustaka Setia.

Yensy. Hasil Belajar. 2012. Penerapan Model Pembelajaran Kooperatif Tipe Group Investigation Dengan Mengunakan Alat Peraga Untuk Meningkatkan Hasil Belajar Siswa Di Kelas VIII Di SMP Negri 1 Agamakmur. 2012, p. 25. 